Research Square

\title{
Molecular Diagnosis of Kallmann Syndrome by Whole Exon Sequencing and Bioinformatic Approaches
}

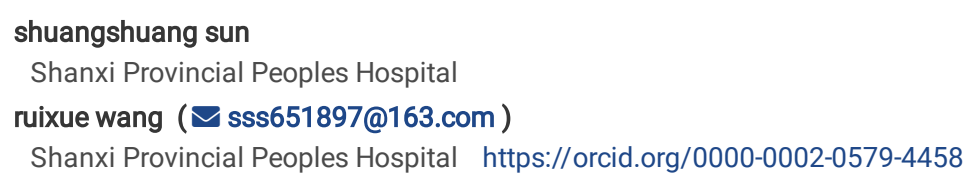

Research

Keywords: Kallmann syndrome, whole-exome sequencing, bioinformatics analysis, IGSF10, KLB, ANOS1

Posted Date: March 6th, 2021

DOI: https://doi.org/10.21203/rs.3.rs-285888/v1

License: () (7) This work is licensed under a Creative Commons Attribution 4.0 International License. Read Full License 


\section{Abstract}

Background: Kallmann syndrome is a hypogonadotropic hypogonadism accompanied by anosmia or hypoxia. More than 10 Kallmann syndrome pathogenic genes have been found. However, only $30 \%$ of the incidence of Kallmann syndrome is related to the above genes, suggesting that there are other diseaserelated genes of KS that have not been found.

Methods $\llbracket$ We studied Kallmann syndrome pathogenesis through high-throughput exome sequencing on four patients with Kallmann syndrome for screening the potential pathogenic sites and exploring the genotype-phenotype correlation. Clinical data and peripheral blood samples were collected from the patients. White blood cells were separated and genomic DNA was extracted. High-throughput sequencing of all exons in the candidate pathogenic genes of the probands was performed, and the results obtained were analyzed.

Results: Sequencing revealed mutations in the KLB, p.T313M, ANOS1, p.C172F, and IGSF10 (p.Lys1819Arg and p.Arg1035Thr) at different sites, which may have been associated with disease onset. Discovery of these sites can improve our understanding of KS pathogenesis and serve as a novel target in further studies on KS.

Conclusion: our analysis found new mutation sites to facilitate follow-up research. Diagnosis of Kallmann syndrome is a challenging, timely diagnosis and treatment can induce puberty, thereby improving sexual, bone, metabolic, and mental health.

\section{Introduction}

Idiopathic hypogonadotropic hypogonadism $(\mathrm{IHH})$ is caused by congenital hypothalamic gonadotropin-releasing hormone (GnRH) neuron deficiency or dysfunction in $\mathrm{GnRH}$ synthesis or secretion, which leads to a reduction in gonadotropin secretion by the pituitary[1]. Low levels of gonadotropin secretion may consequently lead to insufficient gonadal function. This can manifest in the form of underdeveloped secondary sex characteristics, gamete synthesis disorders, and delayed bone closure, among other conditions. According to the clinical symptoms, there are two types: those with impaired sense of smell are called Ka11mann syndrome $\varangle \mathrm{KS} \bigotimes$; those with normal sense of smell are called idiopathic hypogonadotropic hypogonadism (nIHH) with normal sense of smell. Measurement of the levels of gonadotropins (luteinizing hormone, LH; follicle-stimulating hormone, FSH) and imaging examinations can help confirm the diagnosis of $\mathrm{IHH}$. and hormone replacement therapy can be used as a suitable therapeutic strategy.

Kallmann syndrome (Kallmann Syndrome, KS) is a hypogonadotropic hypogonadism accompanied by anosmia (cannot recognize any odor) or hypoxia (recognizable part of a strong pungent odor). It is a disease with clinical and genetic heterogeneity. KS can be familial or sporadic. There are three ways of inheritance: X-linked recessive inheritance, autosomal dominant inheritance, and autosomal recessive inheritance. The pathogenesis of KS is not fully understood. It is currently believed that $\mathrm{GnRH}$ neurons originating from the olfactory substrate cannot migrate normally and locate in the hypothalamus due to various reasons, resulting in complete or partial loss of the ability to synthesize and secrete $\mathrm{GnRH}$, causing hypothalamic-pituitary gonadal axis dysfunction and failure to activate Puberty.

The diagnosis of KS is challenging, especially in early puberty, and the clinical manifestations reflect physical delays in development and puberty. Timely diagnosis and treatment can induce puberty, thereby improving sexual, bone, metabolic, and mental health.

In this study, we reported four cases of clinically confirmed KS along with the investigation of the mutation sites in both patients. The aim is to identify the existing mutation sites and reveal the relationship between genotype and phenotype

\section{Patients And Methods}

\subsection{Ethical compliance}

The study, consistent with the Declaration of Helsinki, was approved by the Ethics Committee of the Shanxi Provincial People's Hospital (Shanxi, china). All persons gave their informed consent prior to their inclusion in the study.

\subsection{Patients}

Patient 1: A 35-year-old woman suffering from amenorrhea for 17 years was hospitalized in March 2018. The patient had menstrual cramps, underdeveloped breasts, sparse armpit and pubic hair, female secondary sexual characteristics, hyposmia , normal intelligence, pubic hair - Tanner II, and breast Tanner - V. Hospitalization was recommended for further diagnosis and treatment. Patient 2: A 24-year-old man diagnosed with sexual underdevelopment 11 years prior was hospitalized in May 2018. The patient first observed at 13 years of age that his penis and testicles were underdeveloped. The patient suffered from spermatorrhea. Secondary sexual characteristics, such as pubic hair, axillary hair, laryngeal knots, and voice changes, among others, were absent. No secondary sexual characteristics were observed. Bilateral breast enlargement was a feminine characteristic observed. Other characteristics included pubic hair

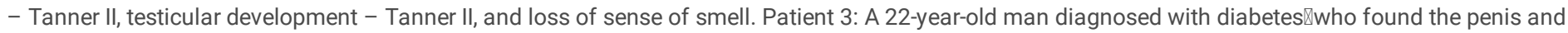
testicles were underdeveloped, secondary sexual characteristics, such as pubic hair, axillary hair, laryngeal knot, among others, were absent. and also with hyposmia. Patient 4: A 16-year-old man diagnosed with diabetes囚also found the penis and testicles were underdeveloped, secondary sexual characteristics, such as pubic hair, axillary hair, laryngeal knot, among others, were absent. and with loss of sense of smell.

\subsection{General clinical data collection}


Data on the medical history of the patients and their family members were collected in detail and analyzed. Physical examination, routine electrocardiogram, and echocardiography were performed and the results were analyzed. laboratory tests were performed with a chemiluminescence instrument(MAGLUMI 4000 PLUS. China)

We also need to do the GnRH stimulation test, first, take blood to check the basic values of LH and FSH, then inject GnRH intravenously, the LH and FSH values were checked 15 minutes, 30 minutes, 1 hour, and 120 minutes later. Observe the dynamic changes of these two hormones.

\subsection{Exome sequencing and bioinformatics analysis}

\subsubsection{DNA extraction}

For DNA extraction, $2 \mathrm{~mL}$ of venous blood sample was collected from each patient and their parents, which were treated with heparin to prevent coagulation. Genomic DNA was extracted according to the instructions provided by the Se Blood DNA kit (Omega Bio-Tek, inc.), and the patients' DNA sample was dispatched to Aiji Taikang for whole-exome sequencing (WES), and their parents' DNA samples were used for sanger sequecing.

\subsubsection{Bioinformatics analysis of WES data}

The raw sequence data obtained was subjected to quality control using FastQC[2]and the clean reads were aligned to the human reference genome (hy19) using Bwa[3]. The duplicate reads were labeled using SAMBLASTER[4], and the results were compared for quality control. We used the GATK HaplotypeCaller[5] for mutation analysis, and data from dbSNP, 1000 Genomes, dbNSFP, and clinVar, among other databases were used to annotate the mutation sites.

\subsubsection{Analysis of mutations and candidate genes}

The following were filtered from the data: population with a mutation frequency greater than $1 \%$, sites in the dbSNP database, and nonsense mutation sites (intron regions, synonymous mutations, and other mutations that do not affect protein function). The FGFR1, FGF8[6,7], GNRHR[8], IGSF10[9], PROK2, PROKR2[10,11], TAC3, TACR3[12], DAX1[13], NSMF[14,15], CHD7[16], SOX2[17], FEZF1[18], HS6ST1[19], SOX10[20], SEMA3A[21], KISS1[22], KISS1R[23], IL17RD[24], and WDR11[25] genes were analyzed for identification of the relevant pathogenic sites. Published literature was search based on the sites selected by PUBMED.

\section{Results}

\subsection{Laboratory data}

In patient 1, the level of 25-hydroxyvitamin $\mathrm{D}$ was found to be $11.78 \mathrm{ng} / \mathrm{mL}$. Liver function, renal function, erythrocyte sedimentation rate, and the levels of electrolytes, calcium, phosphate, parathyroid hormone, and C-reactive protein were normal. Blood osmotic pressure was $297 \mathrm{mOsm} / \mathrm{kg} \cdot \mathrm{H}_{2} \mathrm{O}$ and urine osmotic pressure was $620 \mathrm{mOsm} / \mathrm{kg} \cdot \mathrm{H}_{2} \mathrm{O}$. The growth hormone level was found to be $0.895 \mathrm{ng} / \mathrm{mL}$. No abnormalities were observed in the thyroid function test. The cortisol circadian rhythm pattern was as follows: 08:00 $120 \mathrm{ng} / \mathrm{mL} ; 16: 00106.6 \mathrm{ng} / \mathrm{mL} ; 00: 0013.93 \mathrm{ng} / \mathrm{mL}$. The 24-h urine-free cortisol level was 188.40 $\mu \mathrm{g} / 24 \mathrm{~h}$. Color Doppler ultrasound examination revealed that the uterus size was small. The levels of the following sex hormones were measured: blood prolactin, $94.67 \mu \mathrm{lU} / \mathrm{mL}$; estradiol, $13.7 \mathrm{pg} / \mathrm{mL}$; progesterone, $0.303 \mathrm{ng} / \mathrm{mL}$; testosterone $0.13 \mathrm{ng} / \mathrm{mL} ; \mathrm{LH}<0.1 \mathrm{mlU} / \mathrm{mL} ; \mathrm{FSH} 0.894 \mathrm{mlU} / \mathrm{mL}$.

The GnRH stimulation test revealed that the peak values of $\mathrm{LH}$ and FSH exceeded $1 \mathrm{mIU} / \mathrm{mL}$, which indicated stimulation, see Table 1 . MRI scan of the pituitary and CT scan of the adrenal glands revealed no abnormalities. No abnormal lesions were observed in the uterus and breasts.

The following observations were made in patient 2: ACTH 08:00 91.32 pg/mL; alanine aminotransferase 12.58 IU/L; aspartate aminotransferase 12.81 IU/L; blood creatinine $43.75 \mu \mathrm{mol} / \mathrm{L}$; urine osmotic pressure $898 \mathrm{mOsm} / \mathrm{kg} \cdot \mathrm{H}_{2} \mathrm{O}$; blood osmotic pressure $291 \mathrm{mOsm} / \mathrm{kg} \cdot \mathrm{H}_{2} \mathrm{O}$.

The GnRH stimulation test revealed that the basal values of LH and FSH secretion were low. Both peaked at 120 min, but the values did not exceed $1 \mathrm{mIU} / \mathrm{ml}$, see Table 1. The levels of the following sex hormones were tested: blood prolactin, $201.1 \mu \mathrm{lU} / \mathrm{mL}$; estradiol, $14.12 \mathrm{pg} / \mathrm{mL}$; progesterone, $0.479 \mathrm{ng} / \mathrm{mL}$; testosterone $0.361 \mathrm{ng} / \mathrm{mL} ; \mathrm{LH}<0.1 \mathrm{mIU} / \mathrm{mL} ; \mathrm{FSH} 0.257 \mathrm{mIU} / \mathrm{mL}$. The cortisol rhythm was found to be normal, and MRI scan of the pituitary and CT scan of the bilateral adrenal glands revealed no obvious abnormalities.

In patient 3, Urine protein 2+; urine glucose 3+, ketone body 3+, blood ketone $2.8 \mathrm{mmol} / \mathrm{L}$, the growth hormone level was found to be $0.301 \mathrm{ng} / \mathrm{mL}$. No abnormalities were observed in the thyroid function test. The cortisol circadian rhythm pattern was as follows: 08:00 103.1 ng/mL; $16: 0029.67 \mathrm{ng} / \mathrm{mL} ; 00: 00$ $37.39 \mathrm{ng} / \mathrm{mL}$. The levels of the following sex hormones were measured: blood prolactin, $350.6 \mu \mathrm{lU} / \mathrm{mL}$; estradiol, $21.17 \mathrm{pg} / \mathrm{mL}$; progesterone, $1.07 \mathrm{ng} / \mathrm{mL}$; testosterone $0.46 \mathrm{ng} / \mathrm{mL} ; \mathrm{LH}<0.1 \mathrm{mlU} / \mathrm{mL}$; FSH $0.61 \mathrm{mlU} / \mathrm{mL}$. THE islet function test, see Table 2

The GnRH stimulation test revealed that the peak values of $\mathrm{LH}$ and $\mathrm{FSH}$ exceeded $1 \mathrm{mIU} / \mathrm{mL}$, which indicated stimulation, see Table 1

In patient 4, the growth hormone level was found to be $0.175 \mathrm{ng} / \mathrm{mL}$. No abnormalities were observed in the thyroid function test. The cortisol circadian rhythm pattern was normal. The levels of the following sex hormones were measured: blood prolactin $157.2 \mu \mathrm{lU} / \mathrm{mL}$; estradiol, $5 \mathrm{pg} / \mathrm{mL} ; \mathrm{progesterone,} 0.13$ $\mathrm{ng} / \mathrm{mL}$; testosterone $0.46 \mathrm{ng} / \mathrm{mL} ; \mathrm{LH}<0.1 \mathrm{mlU} / \mathrm{mL}$; FSH $0.91 \mathrm{mlU} / \mathrm{mL}$.

The GnRH stimulation test revealed that the peak values of $\mathrm{LH}$ and $\mathrm{FSH}$ exceeded $1 \mathrm{mIU} / \mathrm{mL}$, which indicated stimulation, see Table 1

\subsection{Genetic testing}

Page $3 / 13$ 
Quality control analysis of the raw WES data (using FastQC) of the two samples is illustrated in Figure 1 . The average quality of the bases was greater than 30 (accuracy greater than $99.9 \%$ ), and the sequence quality was satisfactory.

\subsubsection{Sequence alignment and sequencing depth}

Exome sequencing of the two samples yielded 39M paired-end reads, of which 99\% (mapped reads) sequences could be matched to the human reference genome, and the proportion of duplicate reads was approximately $15 \%$. The average sequencing depth (mean depth) exceeded $130 \mathrm{X}$. see Table 3.

\subsubsection{Extent of variation}

The bioinformatics analysis revealed that the sample from patient 1 had 82,986 SNPs and 13,495 INDELs. Through dbSNP annotation, $99.06 \%$ of the SNPs and $91.15 \%$ of the INDELs could be annotated.

Patient 2 had 84,748 SNPs and 13,931 INDELs. Through dbSNP annotation, $98.98 \%$ of SNPs and $90.98 \%$ of the INDELs could be annotated.

Patient 3 had $84 \llbracket 579$ SNPs and $13 ₫ 760$ INDELs. Through dbSNP annotation, $99.02 \%$ of SNPs and $90.99 \%$ of the INDELs could be annotated.

Patient 4 had 84,731 SNPs and 13,794 INDELs. Through dbSNP annotation, $98.94 \%$ of SNPs and $90.99 \%$ of the INDELs could be annotated. see Table 4 and Table 5

\subsubsection{Analysis of candidate gene mutations}

The gene mutations were filtered according to the following criteria: (1) the mutation should be located in the exon; (2) the mutation should not be synonymous; (3) population frequency should be greater than 0.001 .

After filtering, only two mutation sites were detected (one each in IGSF10, and CHD72 genes) for patient 1, whereas four mutation sites were detected (one each in SOX6, DMXL2, IGSF10, and ANOS1 genes) for patient 2. One mutation sites were detected in the KLB for patient 3هone mutation sites were detected in the ANOS1 for patient 4. Mutations in the IGSF10 gene were common to both patients. Furthermore, the literature search revealed that the genes CHD72, ANOS1, IGSF10, and DMXL2 were also related to IHH.

\subsubsection{Verification of candidate sites}

To verify the pathogenic sites in the four patients, we compared the parental genotypes and found that IGSF10 (p.Lys1819Arg), KLB p.T313M and ANOS1 p.C172F may harbor the pathogenic site, Population data did not reveal the presence of a mutation at this site, and the mutation frequency of p.Arg1035Thr in the gnomAD database was found to be 0.0004 . and the mutation frequency of p.T313M in the gnomAD database was found to be 0.0001 . and the mutation frequency of p.C172F in the gnomAD database was found to be 0 . which is illustrated in Table 6 and Figure 2. List of primer pairs used for PCR, see Table 7.

MutationTaster predicted Lys1819Arg to be a harmful mutation, whereas SIFT_pred and Polyphen2_HDIV predicted Arg1035Thr to be a harmful mutation. whereas SIFT_pred predicted p.C172F to be a harmful mutation. The two mutations of IGSF10 are located in the region encoding the immunoglobulin I-set domain and in the nondomain region. The mutations of ANOS1 are located in the region encoding the WAP domain囚the mutations of KLBare are located in the region encoding the Glyco_hydro_1 domain. 『see Figure 3区

\section{Discussion}

With further research on KS genetics, some genes related to KS pathogenesis have been found, such as KAL1, FGFRI, FGF8, PROKR2, PROK2, the function of these genes may be related to the normal migration of $\mathrm{GnRH}$ neurons and development of the olfactory bulb. However, only $30 \%$ of the incidence of Kallmann syndrome is related to the above genes, suggesting that there are other disease-related genes of KS that have not been found

In this study, WES was performed to analyze the mutant genes and loci in four patients with KS, and two potential pathogenic loci of the IGSF10 gene (p.Lys1819Arg and p.Arg1035Thr) were identified. According to the analysis of the IGSF10 gene mutations in the two patients, the variations included alteration of the amino acid at the 1819th position from lysine to arginine and at the 1035th position from arginine to threonine. The Lys 1819 Arg site is located in the l-set domain of the protein, which is primarily associated with immune function and angiogenesis. The discovery of this site can improve our understanding of KS pathogenesis and serve as a novel target for further studies on KS.

IGSF10 is a member of the immunoglobulin superfamily[26]. While its exact function is yet to be clarified, studies have shown that IGSF10 expression is associated with combined pituitary hormone deficiency. It is also considered a novel prognostic biomarker for breast cancer and lung cancer and has been associated with various diseases, such as primary ovarian insufficiency and endometrial cancer. Mutations in the IGSF10 gene are reportedly associated with abnormal regulation of the migration of GnRH neurons, which may delay puberty and other developmental processes.

Among KS patients, about $90 \%$ of the patients, pubic hair and armpit hair were absent. Bone age lagged behind chronological age in some patients. some have anosmia or hyposmia. Some males has breast hyperplasia. small penis, cryptorchidism and vas deferens lack. Some patients can also be accompanied by other body or organ abnormalities, such as facial cranial midline deformity. Nervous system abnormalities. Musculoskeletal system abnormalities and Other systemic abnormalities 
KLB and KL genes have homology. It is highly expressed in metabolic tissues, especially fat tissues. FGF21 is an endocrine FGF mainly secreted by the liver, which regulates the main metabolic processes such as glucose and lipid metabolism. Endogenous FGF21 regulates the physiological response to starvation and various other metabolic stresses. FGF21 signals through the KLB/FGFR1c receptor complex in a tissue-specific manner. KLB enhances the binding of FGF21-FGFR1c, thereby promoting FGF21 signal transduction by binding FGF21 and FGFR1c to itself through two different sites at the same time. In addition, the competitive binding of FGF8 and b-Klotho to the same site of FGFR1 will facilitate the binding to endocrine FGF21 and inhibit the binding and signal transduction of paracrine FGF8. Most patients with KLB mutations exhibit KS and metabolic defects, such as overweight, diabetes, and dyslipidemia, which are consistent with the metabolic effects of this pathway[27].

ANOS1 gene is a pathogenic gene found to cause $x$-linked KS. It is located on the X chromosome (Xp22.3), which contains 14 exons, adjacent to the pseudoautosomal 1 region (PAR1), which is a highly variable and unstable region on the chromosome. ANOS1 encodes anosmin-1, an extracellular matrix protein. Anosmin-1 consists of a cysteine-rich region (CR domain), a whey acidic protein (WAP)-like domain similar, four consecutive fibronectin type III domains and a $\mathrm{C}$-terminal region rich in basic histidine and proline. Anosmin-1 promotes neuronal cell adhesion, neurite outgrowth, axon guidance, and CNS projection neuron branching. In addition, it is also involved in the migration of many types of neural precursors, including GnRH-producing neurons and oligodendrocyte precursors[28,29]. The ANOS1 mutation is found in patients with familial and sporadic KS. The ANOS1 gene mutation has a low incidence in patients with sporadic KS, but a high incidence in patients with familial KS. In KS patients with ANOS1 mutations, the loss or dysplasia of cryptorchidism and olfactory bulb is high.

In our study, another two potential pathogenic loci of the KLB p.T313M and ANOS1 p.C172F were identified冈it suggests that KS disease with KLB mutation should be alert to the risk of diabetes, and KS disease with ANOS1 mutation is related to X-linked recessive inheritance. Although our analysis is limited to 4 patients with KS, it supports the previous view. and found new mutation sites to facilitate follow-up research

Because KS hyposmia can be manifested in different degrees, therefore, sometimes it is not easy to distinguish $\mathrm{KS}$ and $\mathrm{nIHH}$, especially in patients with hypogonadism, often without careful evaluation of olfactory function. There is genetic evidence that the genes encoding GnRH and kisspeptin receptors are related to $\mathrm{nlHH}$, but not related to the migration of $\mathrm{GnRH}$ neuroendocrine cells (KS patients may have abnormal migration of GnRH neuroendocrine cells), suggesting that $\mathrm{KS}$ and $\mathrm{nlHH}$ may have different inheritance background and pathogenesis

Exon sequencing can be used for studying various diseases. It is useful as a diagnostic tool owing to its low cost and high throughput. The method can be used to detect all mutations in human exons simultaneously. With technological advancements, exon capture has emerged as a useful method. Currently, the chip used has been up to $60 \mathrm{M}$, which can include multiple introns and untranslated regions, and provides valuable information for the study of diseasecausing sites.

\section{Conclusion}

We found mutations in the same disease-causing gene in four patients through WES. This is relatively rare, particularly in diseases in which multiple genes are implicated. This finding also illustrates the value of second-generation sequencing for precision therapy. Correct olfactory judgment combined with genetic testing can diagnose Kalman syndrome in time. timely diagnosis and treatment can induce puberty, thereby improving sexual, bone, metabolic, and mental health.

\section{Declarations}

Authors' contributions: Sun Shuangshuang performed the experiments and wrote the manuscript; Wang Ruixue was involved in processing data. All authors have read and approved the final version of this manuscript.

Consent for publication: Not applicable.

Acknowledgements: We would like to thank the families who participated in this study.

Competing interests: The authors have no conflict of interest to declare

Funding: This research received no specific grant from any funding agency in the public, commercial, or not-for-profit sectors.

Ethics Approval and Consent to participate: The study was approved by the Research Ethics Committee of Shanxi Provincial People's Hospital and complied with the ethical standards of the Declaration of Helsinki as well as the relevant national and international guidelines. Each patient signed an informed consent for the use of their venous blood in the research.

Patient consent for publication: Written informed consent was obtained from each patient.

Availability of data and materials: The data to support the findings of the study are available from the corresponding author upon reasonable request

Authors' information: Department of Clinical Lab, Shanxi Provincial People's Hospital Affiliated to Shanxi Medical University, Taiyuan, 030012, Shanxi Province, Chinal

\section{References}


1. Topaloğlu A. K. (2017). Update on the Genetics of Idiopathic Hypogonadotropic Hypogonadism. Journal of clinical research in pediatric endocrinology, 9(Suppl 2), 113-122. https://doi.org/10.4274/jcrpe.2017.S010

2. Andrews S . Babraham Bioinformatics -FastQC A Quality Control tool for High Throughput Sequence Data[J]. 2013.

3. L Li H, Durbin R. Fast and accurate short read alignment with Burrows-Wheeler transform[J]. bioinformatics, 2009, 25(14): 1754-1760.

4. Faust G G, Hall I M. SAMBLASTER: fast duplicate marking and structural variant read extraction[J]. Bioinformatics, 2014, 30(17): 2503-2505.

5. McKenna A, Hanna M, Banks E, et al. The Genome Analysis Toolkit: a MapReduce framework for analyzing next-generation DNA sequencing data[J]. Genome research, 2010, 20(9): 1297-1303.

6. Men, M., Wu, J., Zhao, Y., et al (2020). Genotypic and phenotypic spectra of FGFR1, FGF8, and FGF17 mutations in a Chinese cohort with idiopathic hypogonadotropic hypogonadism. Fertility and sterility, 113(1), 158-166. https://doi.org/10.1016/j.fertnstert.2019.08.069

7. Wit, J. M., Oostdijk, W., Losekoot, M., et al. (2016). MECHANISMS IN ENDOCRINOLOGY: Novel genetic causes of short stature. European journal of endocrinology, 174(4), R145-R173. https://doi.org/10.1530/EJE-15-0937

8. Zhang, J., Tang, S. Y., Zhu, X. B., et al. (2020). Whole exome sequencing and trio analysis to broaden the variant spectrum of genes in idiopathic hypogonadotropic hypogonadism. Asian journal of andrology, 10.4103/aja.aja_65_20. Advance online publication.

https://doi.org/10.4103/aja.aja_65_20

9. Sarfati, J., Dodé, C., \& Young, J. (2010). Kallmann syndrome caused by mutations in the PROK2 and PROKR2 genes: pathophysiology and genotypephenotype correlations. Frontiers of hormone research, 39, 121-132. https://doi.org/10.1159/000312698

10. Tusset, C., Noel, S. D., Trarbach, E. B., et al (2012). Mutational analysis of TAC3 and TACR3 genes in patients with idiopathic central pubertal disorders. Arquivos brasileiros de endocrinologia e metabologia, 56(9), 646-652. https://doi.org/10.1590/s0004-27302012000900008

11. Seminara, S. B., Oliveira, et al (2000). Genetics of hypogonadotropic hypogonadism. Journal of endocrinological investigation, 23(9), 560-565. https://doi.org/10.1007/BF03343776

12. Pitteloud, N., Durrani, S., Raivio, T., \& Sykiotis, G. P. (2010). Complex genetics in idiopathic hypogonadotropic hypogonadism. Frontiers of hormone research, 39, 142-153. https://doi.org/10.1159/000312700

13. Li, J. D., Wu, J., Zhao, Y., et al (2020). Phenotypic Spectrum of Idiopathic Hypogonadotropic Hypogonadism Patients With CHD7 Variants From a Large Chinese Cohort. The Journal of clinical endocrinology and metabolism, 105(5), dgz182. https://doi.org/10.1210/clinem/dgz182

14. Nie, M., Xu, H., Chen, R., et al. (2017). Analysis of genetic and clinical characteristics of a Chinese Kallmann syndrome cohort with ANOS1European journal of endocrinology, 177(4), 389-398. https://doi.org/10.1530/EJE-17-0335

15. Dai, W., Li, J. D., Zhao, Y., et al (2020). Functional analysis of SEMA3A variants identified in Chinese patients with isolated hypogonadotropic hypogonadism. Clinical genetics, 97(5), 696-703. https://doi.org/10.1111/cge.13723

16. Stark, Z., Storen, R., Bennetts, B., et al (2011). Isolated hypogonadotropic hypogonadism with SoX2 mutation and anophthalmia/microphthalmia in offspring. European journal of human genetics : EJHG, 19(7), 753-756. https://doi.org/10.1038/ejhg.2011.11

17. Turan, I., Hutchins, B. I., Hacihamdioglu, B., et al (2017). CCDC141 Mutations in Idiopathic Hypogonadotropic Hypogonadism. The Journal of clinical endocrinology and metabolism, 102(6), 1816-1825. https://doi.org/10.1210/jc.2016-3391

18. Tusset, C., Trarbach, E. B., Silveira, L. F., et al (2011). Aspectos clínicos e moleculares do hipogonadismo hipogonadotrófico isolado congênito [Clinical and molecular aspects of congenital isolated hypogonadotropic hypogonadism]. Arquivos brasileiros de endocrinologia e metabologia, 55(8), 501-511. https://doi.org/10.1590/s0004-27302011000800002

19. Kurio, N., Saunders, C., Bechtold, T. E., et al. (2018). Roles of Ihh signaling in chondroprogenitor function in postnatal condylar cartilage. Matrix biology : journal of the International Society for Matrix Biology, 67, 15-31. https://doi.org/10.1016/j.matbio.2018.02.011

20. Dai, W., Li, J. D., Zhao, Y., et al (2020). Functional analysis of SEMA3A variants identified in Chinese patients with isolated hypogonadotropic hypogonadism. Clinical genetics, 97(5), 696-703. https://doi.org/10.1111/cge.13723

21. Zhang, Y., Zhang, H., Qin, Y., et al (2015). Mutations in KISS1 are not responsible for idiopathic hypogonadotropic hypogonadism in Chinese patients. Journal of assisted reproduction and genetics, 32(3), 375-378. https://doi.org/10.1007/s10815-014-0424-8

22. Nalbantoğlu, Ö., Arslan, G., Köprülü, Ö., et al (2019). Three Siblings with Idiopathic Hypogonadotropic Hypogonadism in a Nonconsanguineous Family: A Novel KISS1R/GPR54Loss-of-Function Mutation. Journal of clinical research in pediatric endocrinology, 11(4), 444-448. https://doi.org/10.4274/jcrpe.galenos.2019.2018.0230

23. Kurio, N., Saunders, C., Bechtold, T. E., et al (2018). Roles of Ihh signaling in chondroprogenitor function in postnatal condylar cartilage. Matrix biology : journal of the International Society for Matrix Biology, 67, 15-31. https://doi.org/10.1016/j.matbio.2018.02.011

24. Men, M., Wang, X., Wu, J., et al (2020). Prevalence and associated phenotypes of DUSP6, IL17RD and SPRY4 variants in a large Chinese cohort with isolated hypogonadotropic hypogonadism. Journal of medical genetics, jmedgenet-2019-106786. Advance online publication.

https://doi.org/10.1136/jmedgenet-2019-106786

25. Kim, H. G., \& Layman, L. C. (2011). The role of CHD7 and the newly identified WDR11 gene in patients with idiopathic hypogonadotropic hypogonadism and Kallmann syndrome. Molecular and cellular endocrinology, 346(1-2), 74-83. https://doi.org/10.1016/j.mce.2011.07.013

26. Howard, S. R., Guasti, L., Ruiz-Babot, G., et al (2016). IGSF10 mutations dysregulate gonadotropin-releasing hormone neuronal migration resulting in delayed puberty. EMBO molecular medicine, 8(6), 626-642. https://doi.org/10.15252/emmm.201606250

27. Misrahi M. $\beta$-Klotho sustains postnatal GnRH biology and spins the thread of puberty. EMBO Mol Med. 2017 Oct;9(10):1334-1337. doi: 10.15252/emmm.201708180. PMID: 28778954; PMCID: PMC5623834. 
28. Nie M, Xu H, Chen R, Mao J, Wang X, Xiong S, Zheng J, Yu B, Cui M, Ma W, Huang Q, Zhang H, Wu X. Analysis of genetic and clinical characteristics of a Chinese Kallmann syndrome cohort with ANOS1 mutations. Eur J Endocrinol. 2017 Oct;177(4):389-398. doi: 10.1530/EJE-17-0335. Epub 2017 Aug 5. PMID: 28780519.

29. Jiang X, Li D, Gao Y, Zhang X, Wang X, Yang Y, Shen Y. A novel splice site variant in ANOS1 gene leads to Kallmann syndrome in three siblings. Gene. 2020 Feb 5;726:144177. doi: 10.1016/j.gene.2019.144177. Epub 2019 Oct 26. PMID: 31669640.

\section{Tables}

Table $1 \mathrm{GnRH}$ stimulation test result

\begin{tabular}{|c|c|c|c|c|c|c|}
\hline & & 0 & $15 \mathrm{~min}$ & $30 \mathrm{~min}$ & $60 \mathrm{~min}$ & $120 \mathrm{~min}$ \\
\hline \multirow[t]{2}{*}{ Patient 1} & $\mathrm{FSH} 囚 \mathrm{mlU} / \mathrm{ml} \mathbb{}$ & 0.79 & 1.33 & 1.72 & 2.47 & 3.07 \\
\hline & $\mathrm{LH} \rrbracket \mathrm{mlU} / \mathrm{ml} \rrbracket$ & $<0.1$ & 1.38 & 2.32 & 2.714 & 2.67 \\
\hline \multirow[t]{2}{*}{ Patient 2} & $\mathrm{FSH} 囚 \mathrm{mlU} / \mathrm{ml} \mathbb{}$ & 0.32 & 1.19 & 1.26 & 1.61 & 3.07 \\
\hline & $\mathrm{LH} \otimes \mathrm{mIU} / \mathrm{ml} \mathbb{V}$ & $<0.1$ & 0.32 & 0.38 & 0.64 & 1.61 \\
\hline \multirow[t]{2}{*}{ Patient 3} & $\mathrm{FSH} 囚 \mathrm{mlU} / \mathrm{ml} \mathbb{}$ & 0.45 & 1.29 & 1.64 & 1.88 & 2.42 \\
\hline & $\mathrm{LH} \otimes \mathrm{mlU} / \mathrm{ml} \mathbb{}$ & $<0.1$ & 0.84 & 1.02 & 1.36 & 1.53 \\
\hline \multirow[t]{2}{*}{ Patient 4} & $\mathrm{FSH} 囚 \mathrm{mlU} / \mathrm{ml} \mathbb{}$ & 0.78 & 1.30 & 1.64 & 1.84 & 2.02 \\
\hline & $\mathrm{LH} \otimes \mathrm{mIU} / \mathrm{ml} \mathbb{V}$ & $<0.1$ & 0.94 & 1.29 & 1.33 & 1.63 \\
\hline
\end{tabular}

Table 2 Islet function test of patient 3

\begin{tabular}{|c|c|c|c|c|c|}
\hline & O凶 & $30 \mathrm{~min}$ & $60 \mathrm{~min}$ & $120 \mathrm{~min}$ & $180 \mathrm{~min}$ \\
\hline 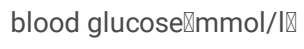 & 7.5 & 9.0 & 15.6 & 18.4 & 13.3 \\
\hline insulin release $\rrbracket u l U / m I \rrbracket$ & 1.50 & 4.55 & 5.26 & 5.79 & 3.88 \\
\hline C-Peptide『ng/mI囚 & 0.27 & 0.47 & 0.59 & 0.84 & 0.62 \\
\hline
\end{tabular}

Table 3 Sequence alignment and sequencing depth

\begin{tabular}{|lllll|}
\hline Sample & Patient 1 & Patient 2 & Patient 3 & Patient 4 \\
\hline Raw reads(PE M) & 36.83373 & 39.8752 & 39.856 & 39.975 \\
\hline reads mapping rate(\%) & 99.59 & 99.58 & 99.64 & 99.65 \\
\hline Target duplication rate(\%) & 14.15 & 14.32 & 14.59 & 14.75 \\
\hline Target mean depth & 130.55 & 139.46 & 151.43 & 145.43 \\
\hline T 10X coverage rate(\%) & 99.57 & 99.6 & 99.45 & 99.27 \\
\hline T 20X coverage rate(\%) & 99.04 & 99.13 & 99.26 & 99.04 \\
\hline T 30X coverage rate(\%) & 97.98 & 98.23 & 98.57 & 98.35 \\
\hline
\end{tabular}

Table 4 Distribution of single-nucleotide polymorphisms 


\begin{tabular}{|c|c|c|c|c|}
\hline Sample & Patient 1 & Patient 2 & Patient 3 & Patient 4 \\
\hline total & 82986 & 84748 & 84579 & 84731 \\
\hline dbsnp & $82205(99.06 \%)$ & $83887(98.98 \%)$ & $83752(99.02 \%)$ & 83835(98.94\%) \\
\hline 1000g_EAS & 77404(93.27\%) & 78717(92.88\%) & $78737(93.09 \%)$ & 78824(93.03\%) \\
\hline ExAC_EAS & $45558(54.90 \%)$ & $45630(53.84 \%)$ & $45773(54.12 \%)$ & $45936(54.21 \%)$ \\
\hline gnomAD_exome_EAS & $45617(54.97 \%)$ & $45698(53.92 \%)$ & $45866(54.23 \%)$ & $46025(54.32 \%)$ \\
\hline gnomAD_genome_EAS & 81924(98.72\%) & $83549(98.59 \%)$ & $83441(98.65 \%)$ & $83536(98.59 \%)$ \\
\hline exonic & $22847(27.53 \%)$ & $23016(27.16 \%)$ & $23100(27.31 \%)$ & $22921(27.05 \%)$ \\
\hline splicing & $239(0.29 \%)$ & $246(0.29 \%)$ & $251(0.30 \%)$ & $259(0.31 \%)$ \\
\hline UTR3 & $3103(3.74 \%)$ & $3161(3.73 \%)$ & $3152(3.73 \%)$ & $3084(3.64 \%)$ \\
\hline UTR5 & $2234(2.69 \%)$ & $2310(2.73 \%)$ & $2305(2.73 \%)$ & $2333(2.75 \%)$ \\
\hline intronic & $48754(58.75 \%)$ & $50084(59.10 \%)$ & $49683(58.74 \%)$ & $50121(59.15 \%)$ \\
\hline intergenic & $1902(2.29 \%)$ & $2108(2.49 \%)$ & $2184(2.58 \%)$ & $2145(2.53 \%)$ \\
\hline upstream & $816(0.98 \%)$ & $881(1.04 \%)$ & $882(1.04 \%)$ & $827(0.98 \%)$ \\
\hline downstream & $371(0.45 \%)$ & $379(0.45 \%)$ & $379(0.45 \%)$ & $366(0.43 \%)$ \\
\hline ncRNA_exonic & $764(0.92 \%)$ & $726(0.86 \%)$ & $730(0.86 \%)$ & $790(0.93 \%)$ \\
\hline ncRNA_splicing & $6(0.01 \%)$ & $8(0.01 \%)$ & $4(0.00 \%)$ & $3(0.00 \%)$ \\
\hline ncRNA_intronic & $1888(2.28 \%)$ & $1764(2.08 \%)$ & $1848(2.18 \%)$ & $1823(2.15 \%)$ \\
\hline synonymous SNV & $11529(13.89 \%)$ & $11613(13.70 \%)$ & $11559(13.67 \%)$ & $11518(13.59 \%)$ \\
\hline nonsynonymous SNV & $10755(12.96 \%)$ & $10727(12.66 \%)$ & $10815(12.79 \%)$ & $10749(12.69 \%)$ \\
\hline stopgain & $85(0.10 \%)$ & $92(0.11 \%)$ & $94(0.11 \%)$ & $84(0.10 \%)$ \\
\hline stoploss & $10(0.01 \%)$ & $10(0.01 \%)$ & $11(0.01 \%)$ & $8(0.01 \%)$ \\
\hline unknown & $483(0.58 \%)$ & $589(0.70 \%)$ & $635(0.75 \%)$ & $576(0.68 \%)$ \\
\hline
\end{tabular}

Table 5 Indel distribution 


\begin{tabular}{|c|c|c|c|c|}
\hline Sample & Patient 1 & Patient 2 & Patient 3 & Patient 4 \\
\hline total & 13495 & 13931 & 13760 & 13794 \\
\hline dbsnp & $12301(91.15 \%)$ & $12675(90.98 \%)$ & $12538(91.12 \%)$ & $12551(90.99 \%)$ \\
\hline 1000g_EAS & $8269(61.27 \%)$ & $8454(60.68 \%)$ & $8378(60.89 \%)$ & $8410(60.97 \%)$ \\
\hline ExAC_EAS & $5560(41.20 \%)$ & $5547(39.82 \%)$ & $5562(40.42 \%)$ & $5637(40.87 \%)$ \\
\hline gnomAD_exome_EAS & $5306(39.32 \%)$ & $5284(37.93 \%)$ & $5286(38.42 \%)$ & $5355(38.82 \%)$ \\
\hline gnomAD_genome_EAS & $12567(93.12 \%)$ & $12991(93.25 \%)$ & $12760(92.73 \%)$ & $12812(92.88 \%)$ \\
\hline exonic & $708(5.25 \%)$ & $733(5.26 \%)$ & $707(5.14 \%)$ & $694(5.03 \%)$ \\
\hline splicing & $199(1.47 \%)$ & $182(1.31 \%)$ & $201(1.46 \%)$ & $192(1.39 \%)$ \\
\hline UTR3 & $669(4.96 \%)$ & $676(4.85 \%)$ & $667(4.85 \%)$ & $661(4.79 \%)$ \\
\hline UTR5 & $375(2.78 \%)$ & $384(2.76 \%)$ & $364(2.65 \%)$ & $373(2.70 \%)$ \\
\hline intronic & $10469(77.58 \%)$ & $10845(77.85 \%)$ & $10712(77.85 \%)$ & $10767(78.06 \%)$ \\
\hline intergenic & $297(2.20 \%)$ & $312(2.24 \%)$ & $309(2.25 \%)$ & $307(2.23 \%)$ \\
\hline upstream & $160(1.19 \%)$ & $187(1.34 \%)$ & $170(1.24 \%)$ & $184(1.33 \%)$ \\
\hline downstream & $51(0.38 \%)$ & $65(0.47 \%)$ & $66(0.48 \%)$ & $68(0.49 \%)$ \\
\hline ncRNA_exonic & $103(0.76 \%)$ & $93(0.67 \%)$ & $102(0.74 \%)$ & $99(0.72 \%)$ \\
\hline ncRNA_splicing & $0(0.00 \%)$ & $2(0.01 \%)$ & $4(0.03 \%)$ & $1(0.01 \%)$ \\
\hline ncRNA_intronic & $407(3.02 \%)$ & $398(2.86 \%)$ & $400(2.91 \%)$ & $391(2.83 \%)$ \\
\hline frameshift insertion & $94(0.70 \%)$ & $103(0.74 \%)$ & $96(0.70 \%)$ & $100(0.72 \%)$ \\
\hline frameshift deletion & $135(1.00 \%)$ & $124(0.89 \%)$ & $132(0.96 \%)$ & $137(0.99 \%)$ \\
\hline nonframeshift insertion & 198(1.47\%) & $216(1.55 \%)$ & $200(1.45 \%)$ & $181(1.31 \%)$ \\
\hline nonframeshift deletion & $217(1.61 \%)$ & $215(1.54 \%)$ & $202(1.47 \%)$ & $203(1.47 \%)$ \\
\hline stopgain & $7(0.05 \%)$ & $8(0.06 \%)$ & $9(0.07 \%)$ & $10(0.07 \%)$ \\
\hline stoploss & $1(0.01 \%)$ & $1(0.01 \%)$ & $0(0.00 \%)$ & $1(0.01 \%)$ \\
\hline unknown & $99(0.73 \%)$ & $106(0.76 \%)$ & $111(0.81 \%)$ & $103(0.75 \%)$ \\
\hline
\end{tabular}

Table 6 Specific information about IGSF10 KLB $\square$ ANOS1 mutation 


\begin{tabular}{|c|c|c|c|}
\hline Type & Patient 1 & Patient 2 & Patient 3 \\
\hline Chr.Start.End & chr3.151161279.151161279 & chr3.151164665.151164665 & chr4.39435942.39435942 \\
\hline Vcf_mut & $\mathrm{T} / \mathrm{C}$ & $\mathrm{C} / \mathrm{G}$ & $\mathrm{C} / \mathrm{T}$ \\
\hline GT & $0 / 1$ & $0 / 1$ & $0 / 1$ \\
\hline$A D$ & $51 / 53$ & $30 / 31$ & $34 / 47$ \\
\hline AAChange.HGVS & $\begin{array}{l}\text { IGSF10:NM_178822.4:5/6:c.5456A>G:p. } \\
\text { (Lys1819Arg) }\end{array}$ & $\begin{array}{l}\text { IGSF10:NM_178822.4:4/6:c.3104G>C:p. } \\
\text { (Arg1035Thr) }\end{array}$ & KLB:NM_175737:exon2:c.C938T:p.T313N \\
\hline cytoBand & $3 q 25.1$ & $3 q 25.1$ & $4 \mathrm{p} 14$ \\
\hline InterVar_automated & Uncertain significance & Uncertain significance & Uncertain significance \\
\hline ACMG(missense only) & PM1,PM2,BP4 & . & PM1,BP4 \\
\hline gnomAD_exome_ALL & & 0.0004 & 0.0001 \\
\hline SIFT_pred & $\mathrm{T}$ & D & T \\
\hline Polyphen2_HDIV_score & 0.011 & 0.981 & 0.036 \\
\hline Polyphen2_HDIV_pred & B & D & B \\
\hline Polyphen2_HVAR_score & 0.056 & 0.69 & 0.016 \\
\hline Polyphen2_HVAR_pred & B & $P$ & B \\
\hline LRT_score & 0.039 & 0 & 0.59 \\
\hline LRT_pred & N & D & $\mathrm{N}$ \\
\hline MutationTaster_score & 0.808 & 1 & 1 \\
\hline MutationTaster_pred & D & N & $\mathrm{N}$ \\
\hline MutationAssessor_score & 0.15 & 2.47 & 2.535 \\
\hline MutationAssessor_pred & $\mathrm{N}$ & M & $M$ \\
\hline FATHMM_score & -0.27 & -0.65 & 1.43 \\
\hline FATHMM_pred & $\mathrm{T}$ & $\mathrm{T}$ & T \\
\hline CADD_raw & 0.585 & 1.94 & -0.287 \\
\hline CADD_phred & 8.054 & 15.84 & 0.711 \\
\hline $\begin{array}{l}\text { fathmm- } \\
\text { MKL_coding_score }\end{array}$ & 0.039 & 0.257 & 0.068 \\
\hline $\begin{array}{l}\text { fathmm- } \\
\text { MKL_coding_pred }\end{array}$ & N & N & $\mathrm{N}$ \\
\hline GERP++_RS & 0.193 & 5.46 & -7.48 \\
\hline
\end{tabular}

Table 7 List of primer pairs used for PCR

\begin{tabular}{|llllll|}
\hline CC & Gene & TemplatelD & ForwardPrimer(Fp) & ReversePrimer(Rp) & $\begin{array}{l}\text { AmpSize } \\
(\mathrm{bp})\end{array}$ \\
\hline Patient 1 & IGSF10 & chr4:39435930-39435950 & ACATTTCCGCCCACATCAGAAG & TCAGCTGTGCCTCTCATCTCAT & 246 \\
\hline Patient 2 & IGSF10 & chr3:151161270-151161285 & TAACAGGTGGTGCTGCAATGAC & AAGCACTGTGGAACTGAAGTGC & 251 \\
\hline Patient 3 & KLB & chr3:151164660-151164670 & AGCAATGTCAGCTTTGGGGAAG & GCTTTGGGAGGCAGAGGAAAAT & 260 \\
\hline Patient 4 & ANOS1 & chrX:8565100-8565108 & TGTGACACTGCATGTGTCTTCAC & TGACCAGCTGTGAGTTCCTCAA & 236 \\
\hline
\end{tabular}

\section{Figures}



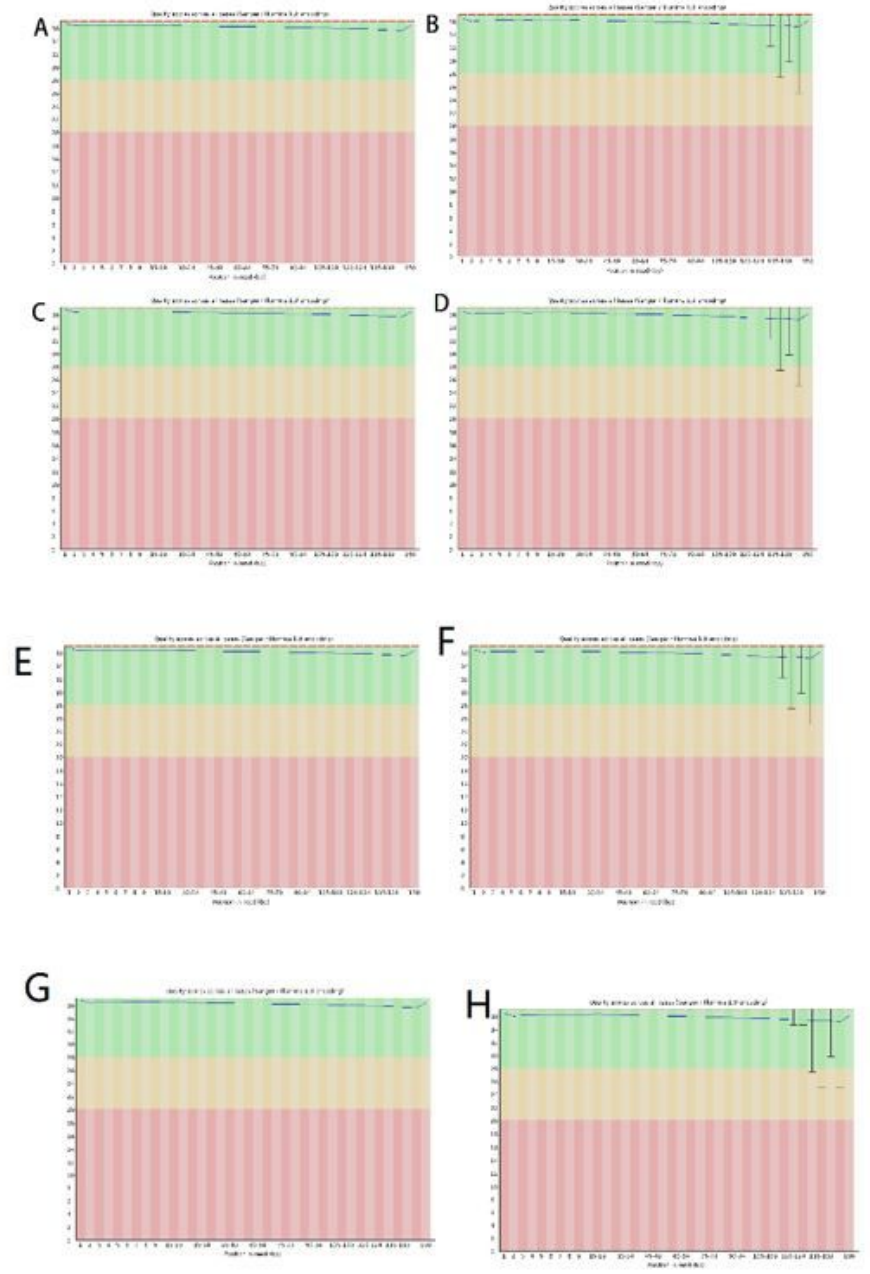

\section{Figure 1}

Original results of exome sequencing A-B is the sequence quality distribution map of reads 1 and 2 of patient 1 . C-D is the sequence quality distribution map of reads 1 and 2 of patient 2 . E-F is the sequence quality distribution map of reads 1 and 2 of patient 3 . G-H is the sequence quality distribution map of reads 1 and 2 of patient 4 . 
A
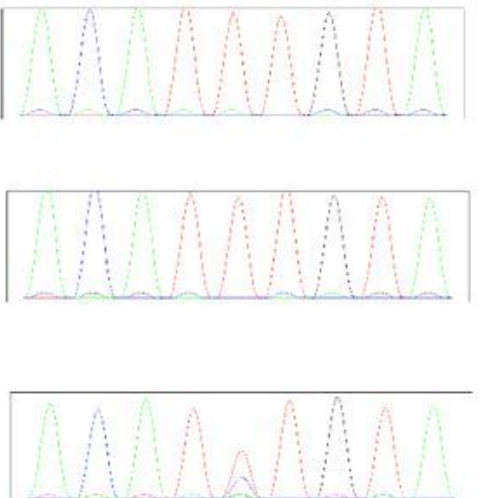

A C A T T T T G T A

C
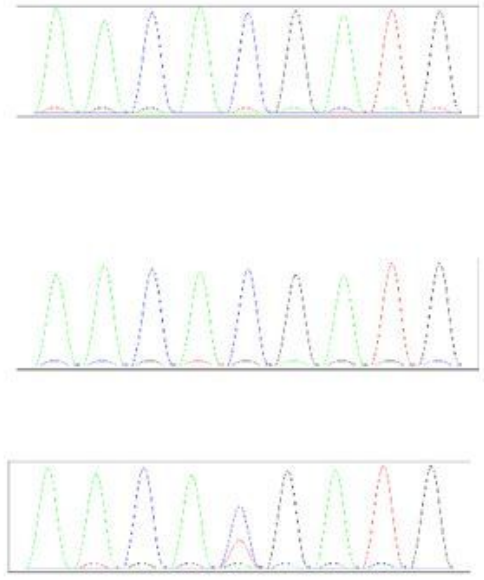

A A C A C G A T G
B
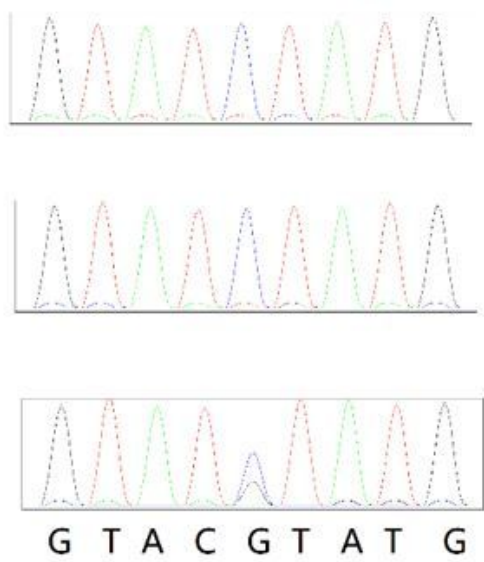

D
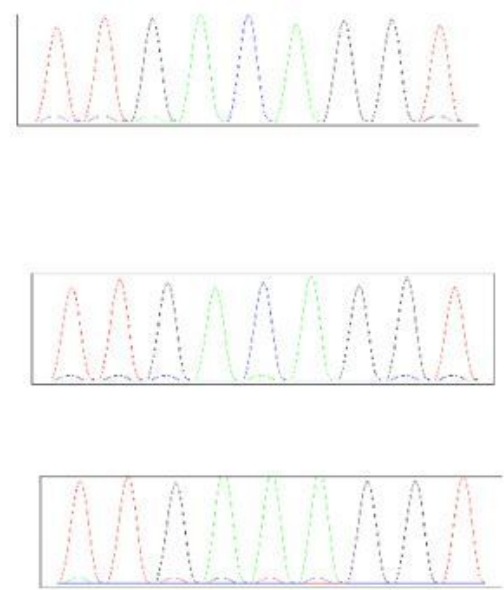

T T G A CA G G T

Figure 2

Sanger sequencing of $4 \mathrm{KS}$ family results. 


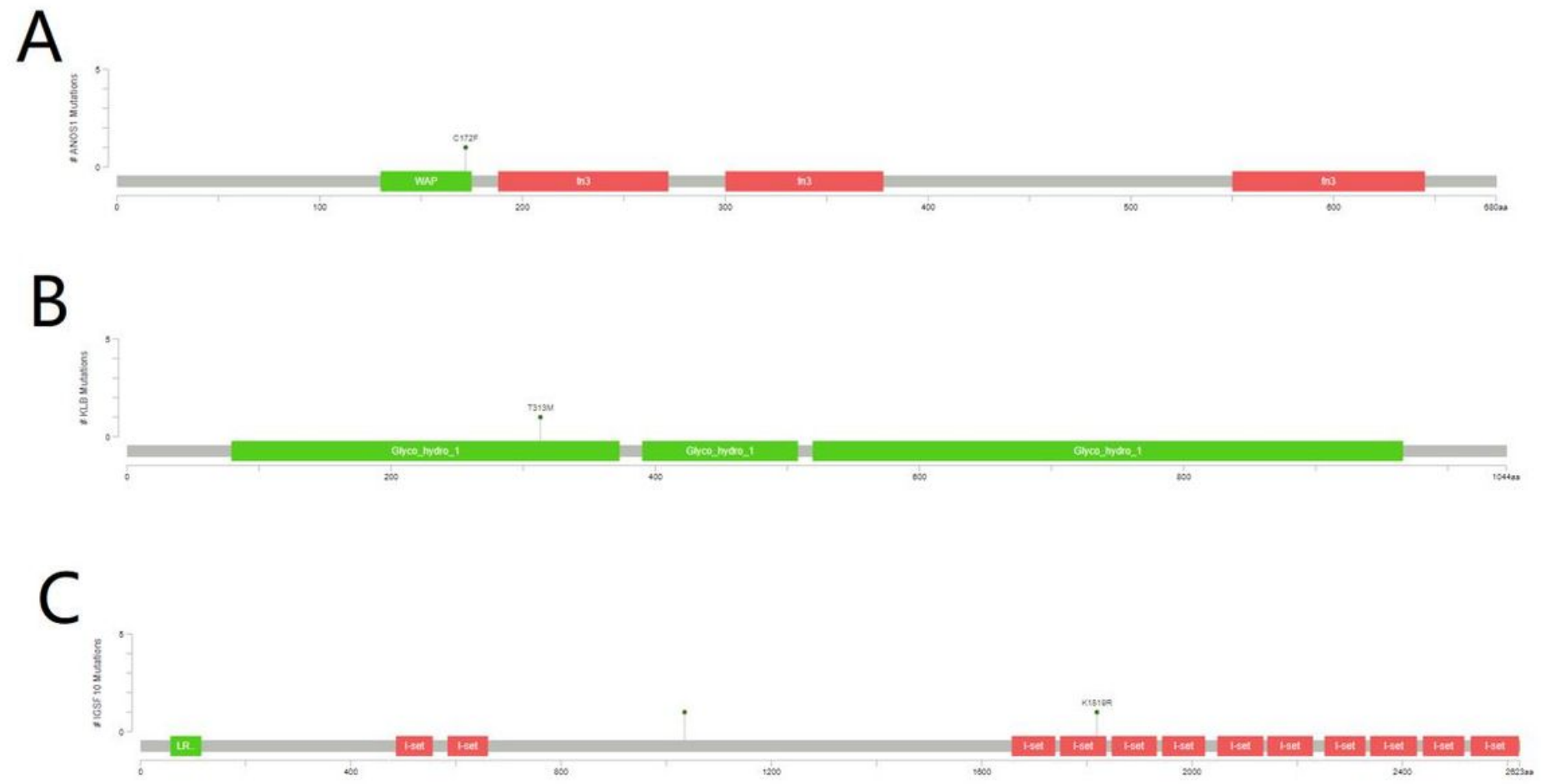

Figure 3

The location of four mutation sites 